\title{
Otimização evolucionária bidirecional aplicada em problemas de transferência de calor
}

\section{João Vítor Mansanares Silva*, Renato Pavanello}

\section{Resumo}

O principal objetivo deste projeto foi o estudo de um método de Otimização Topológica aplicado aos problemas estacionários de transferência de calor. O método de Otimização Topológica foi associado com o método dos Elementos Finitos para a aproximação das soluções do modelo mecânico. Para a Otimização Topológica o método de busca escolhido foi o BESO (Bi-directional Evolutionary Structural Optimization) e foram considerados problemas de minimização da capacidade térmica e minimização de temperaturas locais. $O$ intuito foi obter uma ferramenta computacional de amplo uso, mas acadêmico, que permita resolver o problema de otimização topológica de forma confiável e robusta.

\section{Palavras-chave:}

Otimização, Transferência de calor, BESO.

\section{Introdução}

O uso de métodos numéricos e computacionais de análise e síntese para auxiliar no projeto de máquinas e estruturas é amplamente difundido no meio acadêmico e no meio industrial. Neste trabalho, os métodos numéricos foram aplicados em problemas estacionários de transferência de calor. Para a análise desses problemas foi utilizado o método de Elementos Finitos, que aproxima o campo de temperaturas na estrutura de acordo com as condições de contorno. Para a síntese foi utilizado o método BESO, que encontra uma configuração que suporte as solicitações impostas da melhor maneira possível levando-se em conta as restrições do problema, neste caso, as restrições são a minimização da capacidade térmica e a minimização de temperaturas locais

\section{Resultados e Discussão}

No estudo do método BESO aplicado aos problemas estacionários de transferência de calor o primeiro passo foi discretizar a estrutura em uma malha de elementos finitos e definir as condições de contorno (geração interna de calor, fluxo de calor e/ou convecção de calor).

Depois de definir parte do problema que foi otimizado, o próximo passo foi encontrar o campo de temperaturas resultante das condições anteriormente impostas. Para isso, o MEF, Método dos Elementos Finitos, foi utilizado para resolver a equação de difusão de calor. Através do MEF encontramos a temperatura em cada nó da malha a partir da "matriz de rigidez" e do "vetor força".

O próximo passo foi calcular o número de sensibilidade de cada elemento para o caso de minimização da capacidade térmica e para o caso de minimização de temperaturas locais. Usando uma técnica para suavização do número de sensibilidade foi implementado um filtro para a supressão do problema de tabuleiro de xadrez.

Em seguida o método BESO foi aplicado, adicionando e removendo elementos da malha até atingir o critério de convergência.

Na Figura 1 temos duas estruturas otimizadas resultantes da aplicação do método BESO, a estrutura foi discretizada em uma malha de elementos biliterais como condição de contorno temos que a temperatura nas arestas é igual a zero, no caso (A) temos geração interna de calor sobre toda a malha e no caso (B) temos geração interna de calor pontual (no centro da malha).

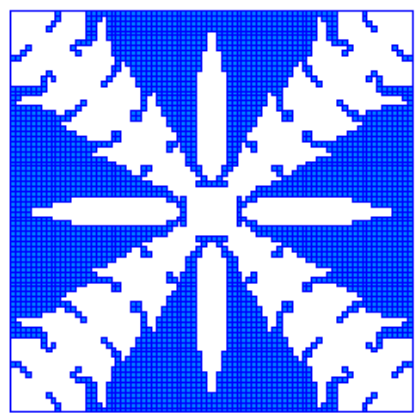

(A)

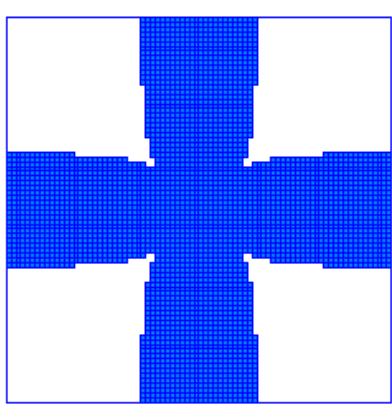

(B)
Figura 1. A) Estrutura otimizada na condição de aquecimento uniforme; B) Estrutura otimizada na condição de aquecimento pontual.

\section{Conclusão}

Este trabalho teve como objetivo estudar a Otimização evolucionária bidirecional aplicada em problemas de transferência de calor e, dentro do que foi proposto, foram obtidos resultados satisfatórios com topologias coerentes e muito próximas às encontradas na literatura.

\section{Agradecimentos}

Ao meu orientador, Prof. Dr. Renato Pavanello, pelo apoio e atenção em todos os momentos necessários.

${ }^{1}$ Quispe Rodriguez, Sergio. Otimização Topológica Multiobjetivo de Estruturas submetidas a carregamentos Termo-Mecânicos. 2015. Tese (Mestrado). Faculdade de Engenharia Mecânica, Universidade Estadual de Campinas, Campinas.

${ }^{2}$ Incropera, Frank, P. Fundamentos de transferência de calor e de massa. LTC, 2008 .

${ }^{3}$ Kwon, Y. W. e Bang, H. The Finite Element Method using MATLAB. CRC Press, 2008 